\title{
The Gendered Impacts of COVID-19 on Labor Markets in Latin America and the Caribbean
}

\section{WORLD BANK}

Gender Innovation Lab for Latin America

and the Caribbean (LACGIL)'

\section{Key Messages}

- According to High-Frequency Phone Surveys (HFPS) conducted in 13 countries in LAC, female workers were 44 percent more likely than male workers to lose their jobs at the onset of the COVID-19 crisis.

- As the crisis evolved, temporarily unemployed workers started to go back to work. But the difference in job losses among females and males persisted.

- Highly female-intensive sectors-trade, personal services, education, and hospitality-explain 56 percent of all job losses.

- Factors associated with resilience to job losses during the crisis differ among males and females. For instance, the presence of school-age children at home is linked with a rise in job losses among females but not among males.

- Employment losses as a result of the COVID-19 pandemic may deepen existing gender gaps in the region, thereby creating the need to design policy responses and actions that target women and help ensure an inclusive recovery.

\section{The context}

Across the globe, women often face lower income opportunities relative to men. The COVID-19 pandemic is establishing new dynamics that may exacerbate the existing gender gaps in economic opportunities in the region. Social distancing measures have disrupted social and economic activities, impacting the income-generating capacity of households. Evidence on previous epidemics suggests that this type of shock threatens to roll back gains in women's economic opportunities (de Paz et al. 2020).

Females hold a disproportionate share of occupations requiring face-to-face interactions, such as in retail, personal care, and tourism, making them less likely to work from home and prone to becoming unemployed. Females are more likely than males to be employed in the informal sector and in other vulnerable forms of employment. Women also tend to do more unpaid household work than men (about 2.7 hours a day). During the pandemic, unpaid care work has risen because children are out of school, the elderly are experiencing greater care needs, and health services are overwhelmed (World Bank 2020).

Without well-informed and timely policy responses, the crisis could widen gender gaps that persist in the region despite $\mathbf{3 0}$ years of progress. In the region, for instance, labor force participation among women has risen over the past three decades (from 41 percent in 1990 to 53 percent in 2019). This has led to improvements in female labor earnings and poverty reduction. But gender gaps persist in the region. Men are still far more likely than women to participate in the labor force, have formal employment, hold higher-quality jobs, and work in higher-paying sectors. In addition, women-particularly young women-are more likely to be unemployed (World Bank 2020).

\section{Gender Innovation Lab for Latin America and the Caribbean (LACGIL)}

The LACGIL supports impact evaluations and inferential research to generate evidence on what works in closing gender gaps in human capital, economic participation, social norms, and agency. Additionally, the lab disseminates findings to improve operations and policy making in the design of cost-effective interventions that tackle gender inequalities and drive change.

To accomplish this, the LACGIL works in partnership with World Bank units, aid agencies and donors, governments, nongovernmental organizations, private sector firms, and researchers. 
This note explores the impacts of the COVID-19 crisis on labor outcomes among males and females and identifies the dimensions that render workers more resilient to job losses. These findings are then used to discuss implications for policymaking. To overcome the scarcity of data generated by the pause in most statistical operations resulting from social-distancing measures, High-Frequency Phone Surveys (HFPS) collected in the region by the Poverty and Equity Global Practice of the World Bank are used. In this way, the note aims to estimate the gendered outcomes in the labor markets associated with the deepest recession since World War II.

\section{The data}

Between May 2020 and August 2020, three waves of phone surveys were conducted in 13 countries in LAC to assess the impacts and transmission channels of the COVID-19 crisis in the region. ${ }^{2}$ The first round of surveys was conducted in May 2020 (two months after most countries in $\mathrm{LAC}^{2}$ had declared quarantines, in mid-March 2020). The second wave was collected between June 2020 and July 2020, and the third between July 2020 and August 2020. The surveys included modules on labor

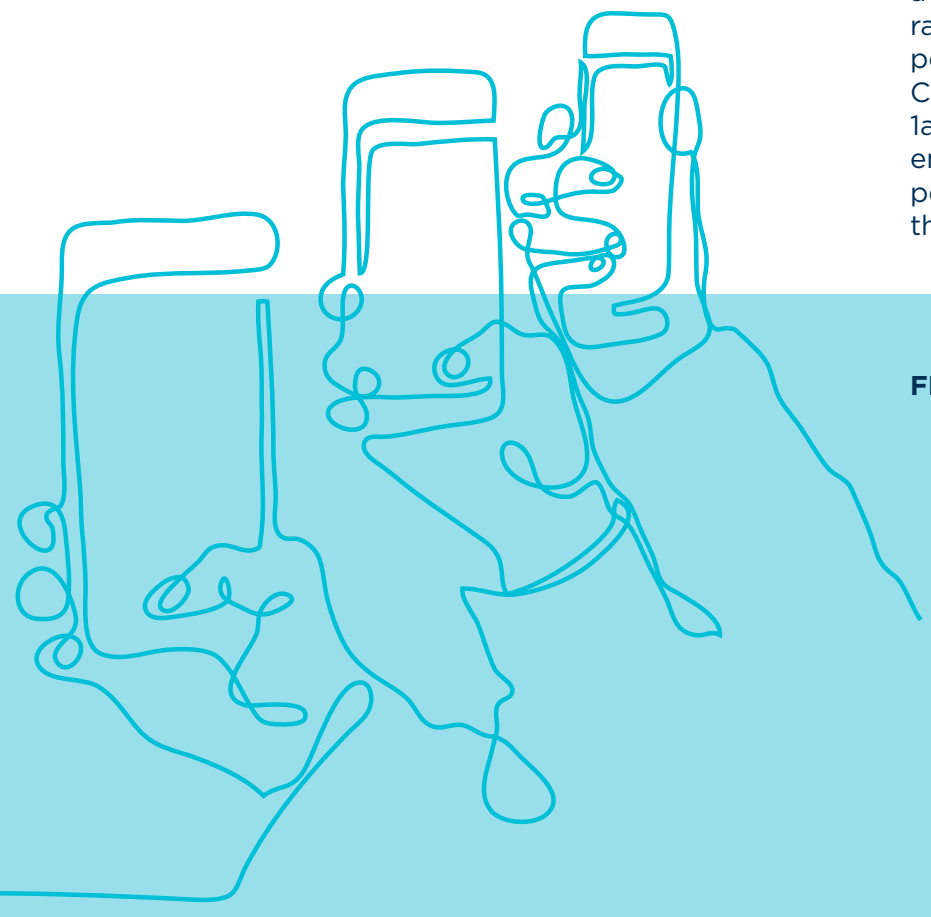

\section{DEFINITIONS}

- The analysis is conducted at the regional level by pooling the data on the 13 countries. The countries included in the sample are Argentina, Brazil, Bolivia, Colombia, Costa Rica, Chile, Dominican Republic, El Salvador, Guatemala, Honduras, Mexico, Peru, and Paraguay. Females account for 54 percent of the sample. Consistent with data on the entire region, including the countries outside the sample, men were more likely than women to be employed before the COVID-19 outbreak.

- The analysis focuses on individuals who were employed before the pandemic unless otherwise noted.

Job loss or unemployment is defined as not working during the week before the survey.

A temporary job loss has occurred if a respondent reports a job loss but has a job to go back to.

A permanent job loss has occurred if a respondent reports a job loss and has no job to return to.

- Total job losses (the sum of temporary and permanent job losses) have implications for labor income and welfare.

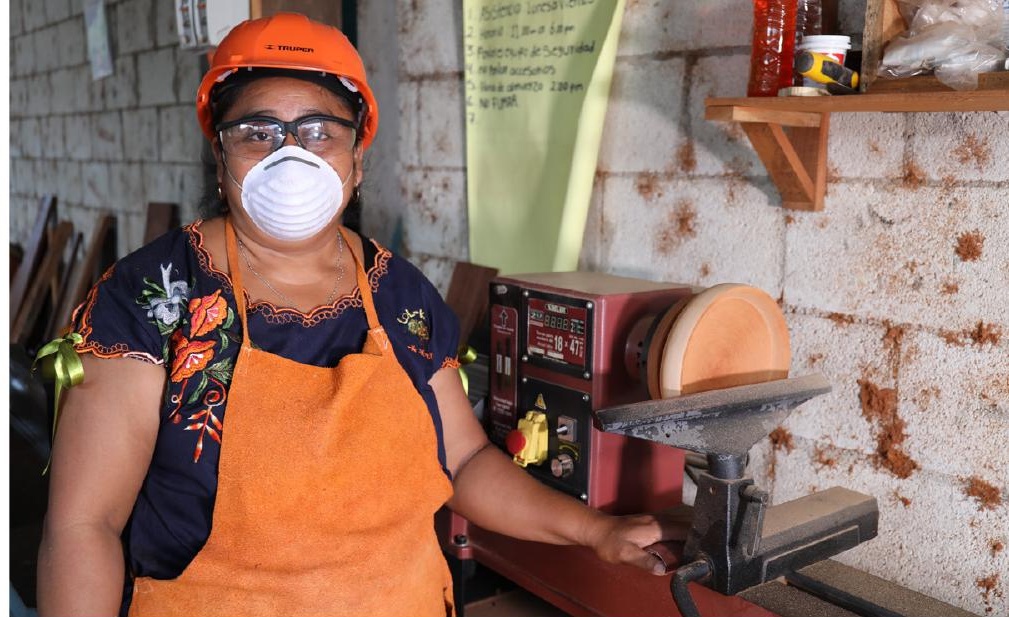

markets, changes in household incomes, access to services, behaviors, and knowledge around COVID-19, and demographic and household characteristics.

The sample covers an average of 1,000 individuals per country (a total of 13,152 observations) who were followed during three rounds of data collection. ${ }^{3}$ The sample in each country is nationally representative of individuals ages 18 or more who have access to a phone. The data are derived from probabilistic sampling using random digit dialing. ${ }^{4}$ The weights have been calibrated to incorporate population projections of the United Nations Economic Commission for Latin America and the Caribbean (ECLAC). Figure $1 a$, shows that 63 percent of females reported they had been employed before the pandemic; the share among men was 84 percent. Thus, in the sample, females represented 45 percent of the employed population before the pandemic (figure 1, panel b).

FIGURE 1, A. PRE-COVID-19 EMPLOYMENT RATE, BY GENDER

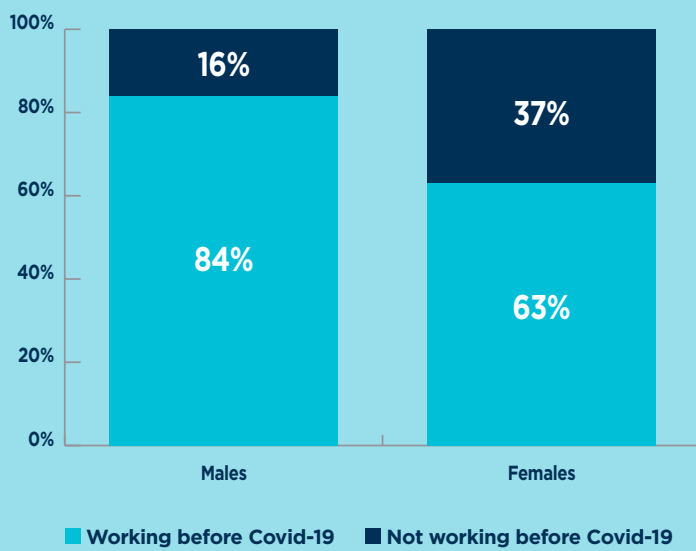

FIGURE 1, B. PRE-COVID-19 SHARE OF THE EMPLOYED POPULATION THAT REPRESENTS EACH GENDER

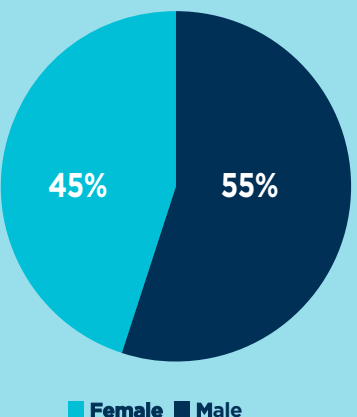

Source: Data of HFPS, wave 1 


\section{What did the study find?}

\section{The uneven burden of job losses}

The COVID-19 crisis has disproportionally affected women, and this difference has persisted. Approximately two months after governments had established quarantines in most countries, the first round of data collection took place. This round shows that 56 percent of workers had lost their jobs either temporarily or permanently. This is 44 percent higher than the corresponding rate among men, 39 percent (figure 2). The employment gap, defined here as the difference between the female and male unemployment rates, stood at 16 percentage points.

Data from the second and third rounds show that, as individuals started to go back to work, temporary but not permanent job losses declined. However, the gap between men and women remained virtually unchanged. By the third round of data collection in August 2020, the difference in total job losses between men and women was still 15 percentage points, and the permanent job loss rate affected one woman in five.
The depth and breadth of the shock on women are observed across all countries in the sample. Figure 3 shows that, in all countries in the sample, women are more likely than men to lose their jobs between round 1 and round 3 . The figure focuses on individuals who were employed before the pandemic and plots, for each country, the percentage of women (green) and men (yellow) who lost their jobs during the crisis either temporarily or permanently. The gray bar represents the employment gap. The figure is organized by country and survey round (first and third) and sorted by the level of the employment gap in the first round. Figure 3 also suggests that not all countries have been affected equally. In the first round at the onset of the crisis, the highest gender gaps were found in Honduras and Costa Rica, where women were 25 percentage points more likely than men to be unemployed. Bolivia and Peru exhibited the narrowest gap (10 and 11 percentage points, respectively), but some of the highest overall unemployment rates in the region.

FIGURE 2.: FEMALE WORKERS ARE MORE LIKELY THAN MALE WORKERS TO FACE TEMPORARY AND PERMANENT JOB LOSSES

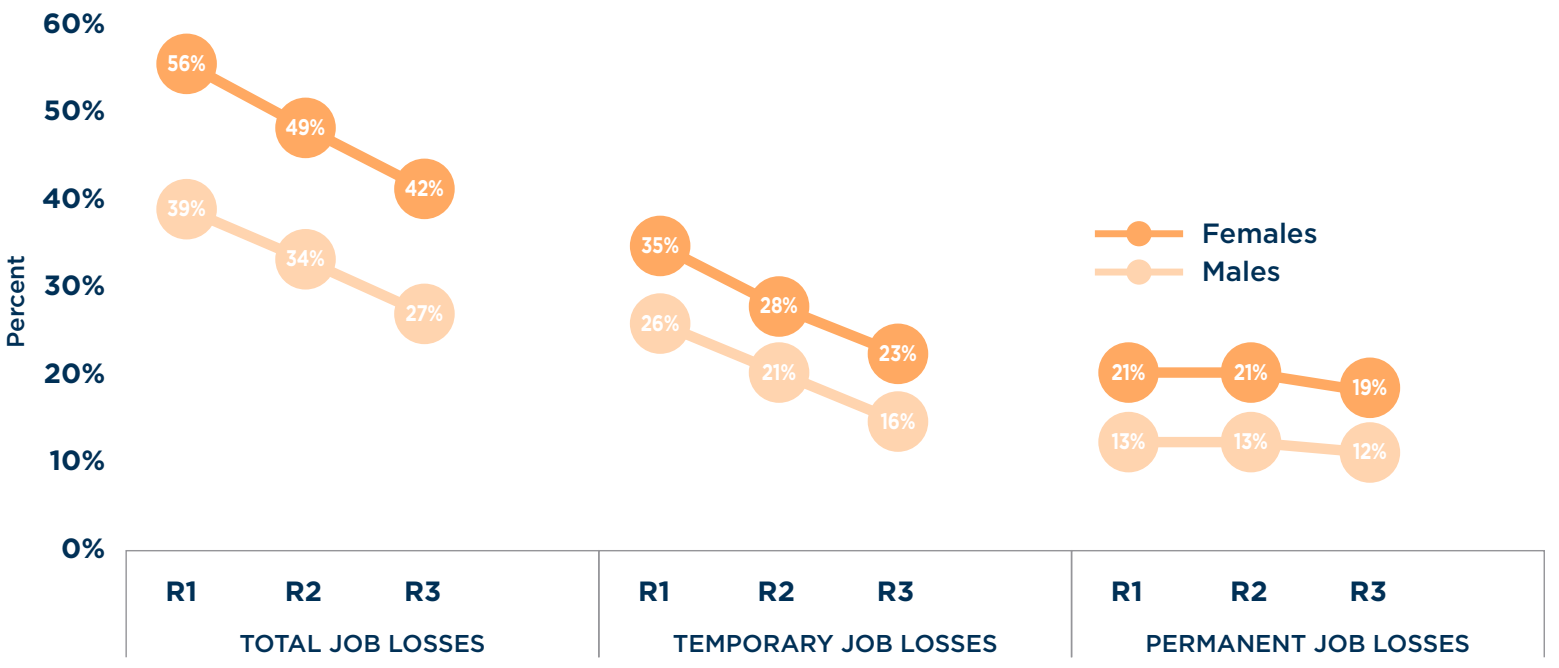

Source: Data of HFPS, waves 1-3.

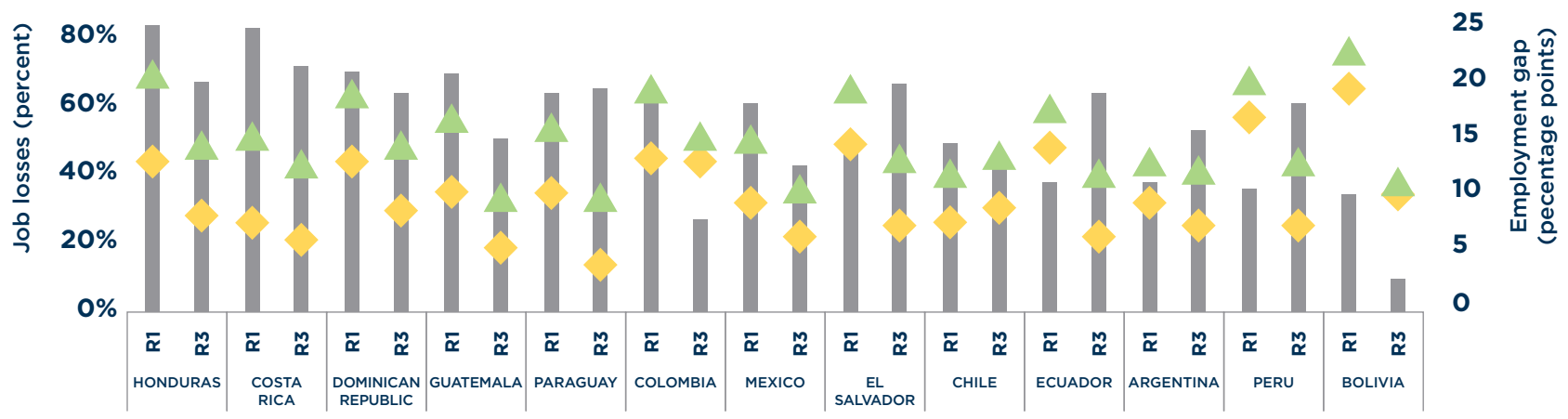

Gender gap (right) Male Female 


\section{What is driving employment losses?}

Women tend to work in sectors that rely more heavily on face-to-face interactions and are thus more vulnerable to social distancing measures. Indeed, the most female-intensive sectors explain most of the observed job losses (figure 4). Although the impacts vary by sector, 56 percent of the job losses were concentrated in trade, personal services, education, and hotels and restaurants, according to the first wave of data collection. These are four of the five most highly female-intensive sectors, employ- ing 60 percent of females before the crisis. This pattern suggests that gender gaps in labor outcomes are being exacerbated as a result of the COVID-19 crisis. Job losses among females not only widen economic gender gaps but also might exacerbate other intrahousehold imbalances by reducing women's empowerment, lessening women's intrahousehold bargaining power, and aggravating intimate partner violence (Manser and Brown 1980; Perova and Reynolds 2017).

\section{FIGURE 4. THE MOST FEMALE-INTENSIVE SECTORS EXPLAIN A LARGE SHARE OF THE TOTAL JOB LOSSES}

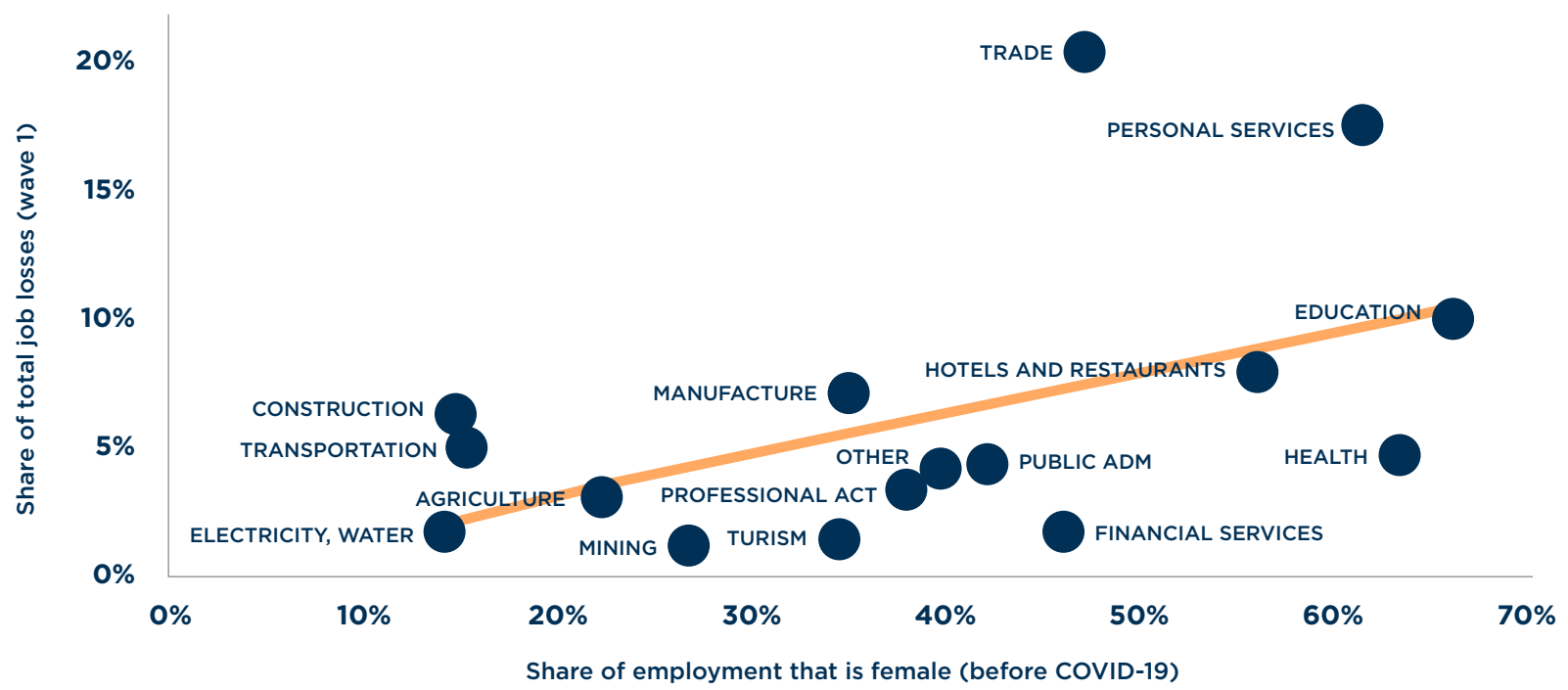

Source: Data of HFPS, wave 1.

Note: Job loss is defined as not working during the week before the survey.

Pre-pandemic wage employment, Internet access, and education are found to increase the probability of remaining employed, but some effects are different among men and women (figure 5) Using a multivariate regression approach, the study explores the factors that correlate with the probability of remaining employed through the pandemic (that is, across the three survey waves). 5 Relative to self-employment, pre-pandemic wage employment is associated with a greater likelihood of remaining employed after the COVID-19 crisis, and this is the largest difference found in the model. It is likely that pre-pandemic wage employment operates through the increased job security that formal jobs offer and the ability of firms to adapt to the crisis relative to self-employees, who are more likely to own informal firms.

The study finds that internet access, which facilitates the possibility of working remotely, is an important determinant of employment during the pandemic. The results show that access to the Internet raises the probability of remaining employed. However, the effect is not statistically significant among women. This may be explained by the fact that, before the COVID-19 crisis, women worked mostly in sectors that require face-to-face interactions, which are associated with types of work that are less likely to be conducted remotely.

Additionally, the analysis finds that high educational attainment is associated with greater resilience to job loss. ${ }^{6}$ This result may be related to the type of work carried out by well educated workers. Such workers may be involved in performing relatively more nonroutine cognitive employment tasks. These results may also be consistent with the higher productivity of more highly educated workers and the evidence that unemployment decreases as the years of education rise.

Women are more likely than men to lose jobs because of increased childcare household needs given that social norms encourage women to become the primary family caregivers. Although the presence of school-age children in the household is not a factor associated with the probability of remaining employed two months after the onset of the COVID-19 crisis (May 2020) (figure 6), caregiving became a more relevant factor associated with job losses as the pandemic persisted. ${ }^{8}$

\section{FIGURE 5. FACTORS ASSOCIATED WITH REMAINING EMPLOYED DURING THE CRISIS}
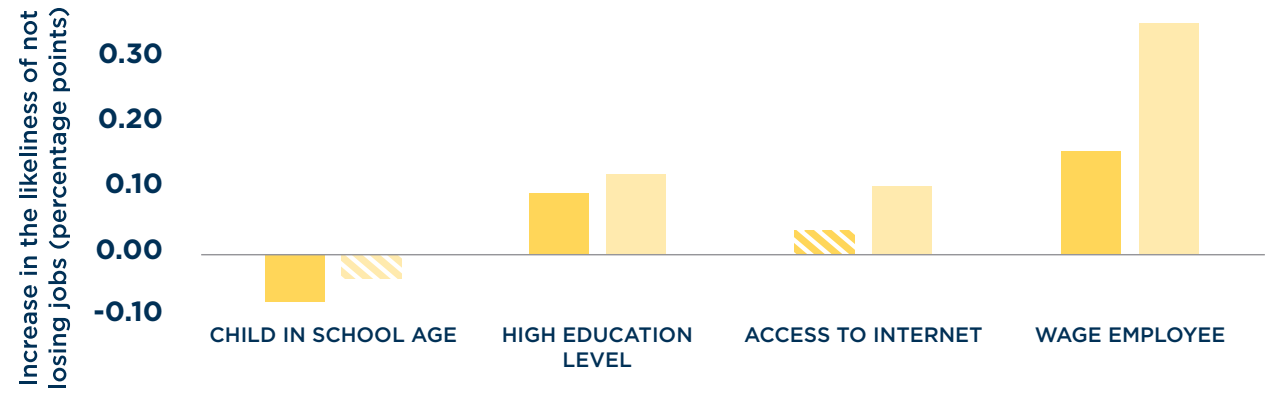

Female Male

Source: Data of HFPS, waves 1-3. Note: The bars represent the coefficient of selected variables in a multivariate regression. The diagonal stripes indicate a lack of statistical significance $(p>1)$.

${ }^{5}$ The analysis relies on a linear probability model estimated by ordinary least squares. The dependent variable is a dichotomous variable that indicates whether the individual remained employed across the three rounds of data collection. The analysis is restricted to individuals employed before the pandemic. The following explanatory variables are included: fixed effects for country, industry, age in years, household composition (number of male household members, number of female household members, number of household members ages 65 or more), number of bedrooms (which, together with household composition, can be interpreted as a proxy for wealth), and type of job (self-employed, wage employee, family business, and other), and dummy variables for urban residence, high educational attainment (measured as completion of at least secondary education), access to the Internet, and whether a school-age child is in the household (defined as children ages 5-18). The model is estimated separately for males and females. 
0.10

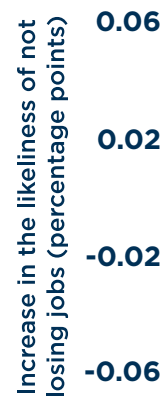

nim

$-0.10$
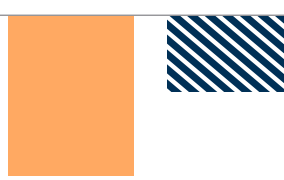

ROUNDS 1 TO 3
Female

Male

Source: HFPS, waves 1-3.

Note: The two bars on the left represent the coefficient of selected variables in a multivariate regression on the likelihood of retaining a job during the first survey round. The two bars on the right represent the coefficient of selected variables in a multivariate regression on the likelihood of retaining a job over the three waves of data collection. The diagonal stripes indicate a lack of statistical significance $(p>.1)$

\section{First signs of recovery?}

Most sectors do not show signs of a recovery among female workers as of August 2020, and those that do mostly involve lower-quality jobs. Only 42 percent of individuals who had returned to work by August 2020 and who had been employed pre-COVID-19 are working in the same sectors in which they had worked before the pandemic. Essential sources of employment among women, such as trade, personal services, and education, are still at considerably low levels of operation. Also, the distribution of women workers across types of jobs has changed. Before COVID-19, 61 percent of female workers were employed as paid employees, and 33 percent were self-employed (figure 7, panel a). By August 2020, 53 percent were paid employees, and 38 percent were self-employed (figure 7 , panel b).

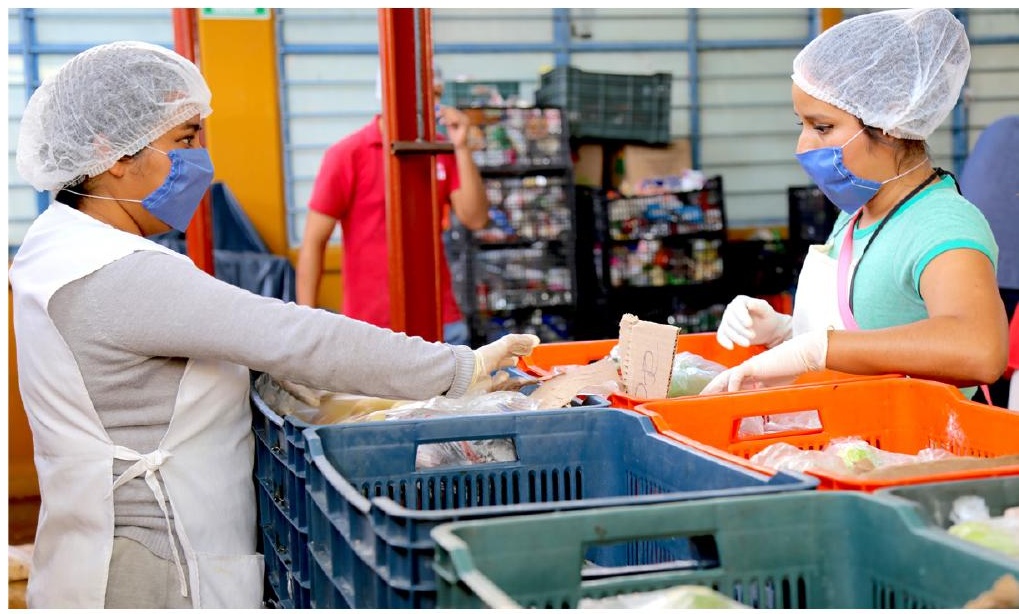

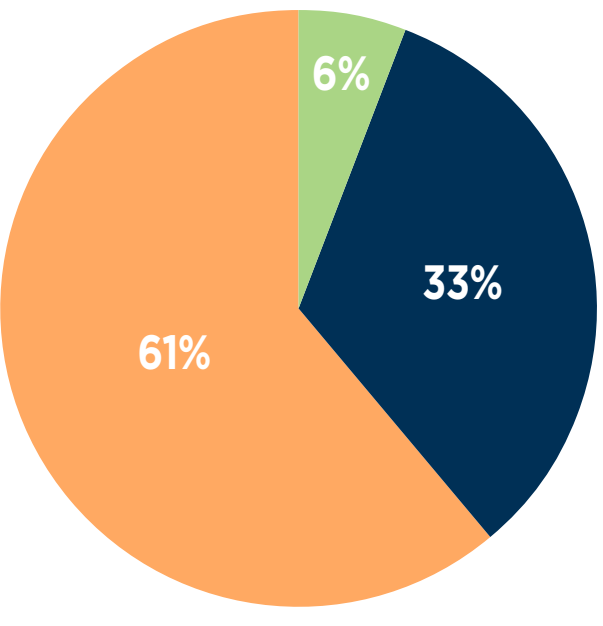

Self-employed
Employee

Other
FIGURE 7, B. TYPE OF EMPLOYMENT AFTER COVID-19

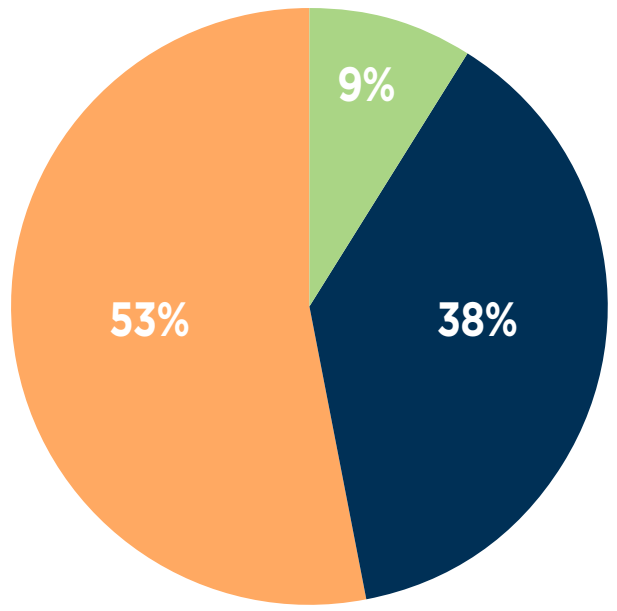

Self-employed Employee Other 


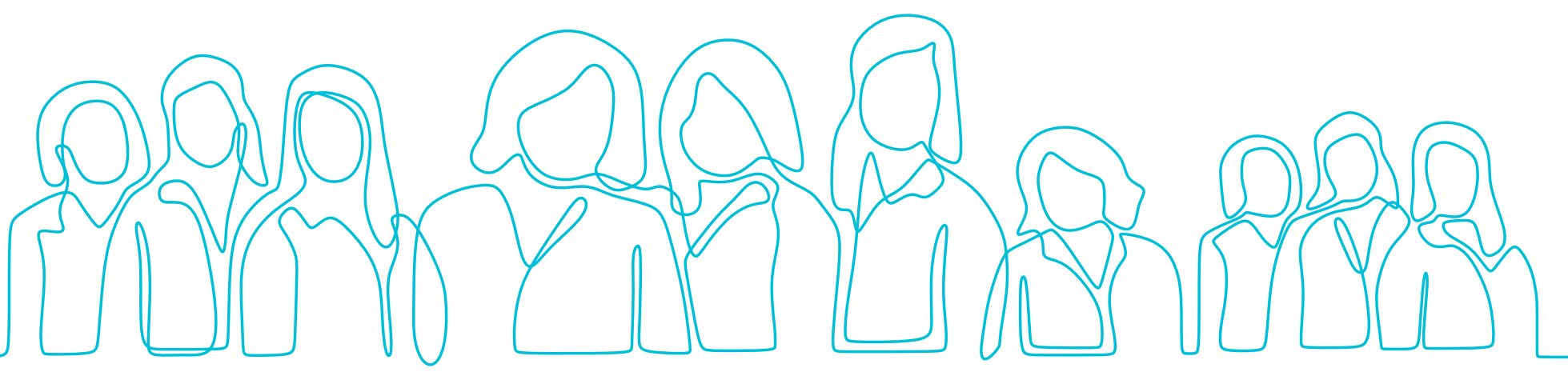

\section{Policy}

\section{recommendations}

\begin{abstract}
- The COVID-19 pandemic has the potential to widen existing gender gaps in economic opportunities. This note shows that gender gaps in LAC are being worsened as a consequence of the pandemic. Understanding the gender implications of COVID-19 is key to informing the design of effective policy responses. Effective responses and actions should focus on creating the conditions and the incentives for women to work. Given women's greater involvement with the care of children and the elderly, as well with household tasks, policies may incorporate elements aimed at restoring household dynamics and incentives that encourage women to work. The findings of this note suggest that policy should encompass recovery plans with a gender angle.
\end{abstract}

- Implementing safety net programs that target the most affected women during the crisis: female-headed households, informal and domestic workers who do not benefit from social protection coverage, and unemployed females; could help households mitigate the negative shock and continue to invest in children (Vandeninden et al., 2019; Rutkowski, 2020). Moreover, cash transfer programs may also support self-employed women in restarting their businesses, considering that most female-intensive sectors are also more prone to be affected negatively by social distancing measures (de Paz et al, 2020). Furthermore, social programs could include training and coaching components, incentives for formalization, business plan competitions, and access to finance (Rutkowski and Bousquet 2019). Since cash transfers can be implemented with limit person-to-person interactions and at a low cost, they can be effective measures to implement in a COVID-19 context.

- In the medium term, policies could aim to raise the resilience of self-employed and less well educated workers, especially women. This might include providing liquidity and other financial support through lines of credit or financial services for women-owned firms. These initiatives may be also combined by training and mentoring provision, incentives for formalization, business plan competitions (Rutkowski and Bousquet, 2019). Additionally, policies might also facilitate access to formal caregiving support and elderly care after economic activities outside the household resume and promote measures to recognize, reduce, and redistribute the burden of unpaid work within households (Vaeza, 2020).

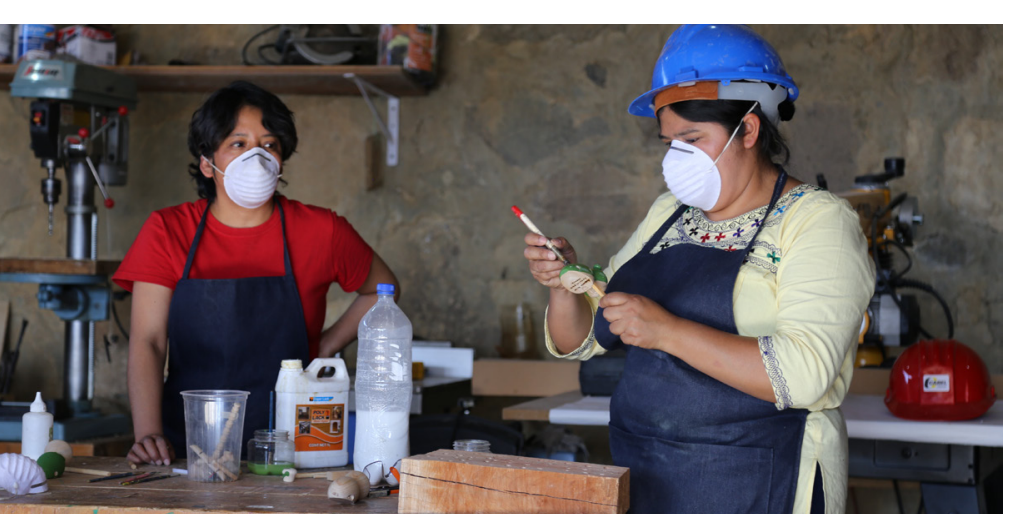

- Ensuring the availability of disaggregated and representative data may help in the design of more specific and well targeted policies. Country-specific policies may be needed to maximize the impact of policy actions. HFPS data can be used at the country level to identify specific gender gaps and tailor policy responses. The transmission channels identified in this note are focused on the economic conditions of women. However, the COVID-19 crisis may also be influencing women's agency and human endowments, such as through health care and education. This possibility drives the need for gender disaggregated and representative data that can assist in measuring the impact of the crisis on such dimensions. These dimensions include school dropouts and educational attainment, early childhood development among boys and girls, access to health care services, time spent doing household chores, potential changes in social norms and attitudes, and the greater risk of violence against women and girls.

\section{STAY CONNECTED}

Visit the LACGIL website for more information.

E-mail: lacgenderlab@worldbank.org

\section{ACKNOWLEDGMENTS}

This work has been funded by the Umbrella Facility for Gender Equality (UFGE), which is a multidonor trust fund administered by the World Bank to advance gender equality and women's empowerment through experimentation and knowledge creation aimed at helping governments and the private sector focus policies and programs on scalable solutions with sustainable outcomes. The UFGE is supported with generous contributions from Australia, Canada, Denmark, Germany, Iceland, Latvia, the Netherlands, Norway, Spain, Sweden, Switzerland, the United Kingdom, the United States, and the Bill and Melinda Gates Foundation.

The findings, interpretations, and conclusions expressed in this brief are entirely those of the authors. They do not necessarily reflect the views of the World Bank, its affiliated organizations, the Executive Directors of the World Bank, or the governments they represent.

This material should not be reproduced or distributed without the World Bank's prior consent. GENDER EQUALITY

1818 H. St NW

Washington, DC 20433 


\section{REFERENCES}

de Paz, Carmen, Miriam Müller, Ana María Muñoz-Boudet, and Isis Gaddis. 2020. "Gender Dimensions of the COVID-19 Pandemic." Policy Note (April 16), World Bank, Washington, DC.

Manser, Marilyn, and Murray Brown. 1980. "Marriage and Household

Decision-Making: A Bargaining Analysis." International Economic Review 21

(1): 31-44.

Perova, Elizaveta, and Sarah Anne Reynolds. 2017. "Women's Police Stations and Intimate Partner Violence: Evidence from Brazil." Social Science and Medicine 174 (February): 188-96.

Reynolds, Sarah Anne, Elizaveta Perova, and Ian M. Schmutte. 2020. The Gender Wage Gap and Violence Against Women in Brazil. Work in progress. World Bank, Washington, DC.

Rutkowski, Michal. 2020. "How Social Protection Can Help Countries Cope with COVID-19." World Bank Blogs: Voices, April 15. https://blogs.worldbank.org/voices/how-social-protection-can-help-countries-cope-covid-19.

Rutkowski Michal, and Franck Bousquet. 2019. "Social Protection: Protecting the Poor and Vulnerable during Crises." World Bank Blogs: Development for Peace, December 12. https://blogs.worldbank.org/dev4peace/social-protection-protecting-poor-and-vulnerable-during-crises.

Vaeza, María Noel. 2020. "Gender and COVID-19 in Latin America and the Caribbean: Integrating Gender into the Response Framework." Regional Office for the Americas and the Caribbean, UN Women, Clayton, Panama City, Panama.

Vandeninden, Frieda, Rebekka Grun, and Amina Semlali. 2019. The Way Forward for Social Safety Nets in Burkina Faso. Washington, DC: World Bank.

World Bank. 2020. "Closing Gender Gaps in Latin America and the Caribbean.” Report 128525, World Bank, Washington, DC.

Copley, A., Decker, A., Delavelle, F., Goldstein, M., O'Sullivan, M., \& Papineni, S. (2020). COVID-19 Pandemic Through a Gender Lens. 